\title{
Reconstruction of the Upper Extremity in Tetraplegia: Functional Assessment, Surgical Procedures and Rehabilitation
}

\author{
A. Vanden Berghe, MD, M. Van Laere, MD, S. Hellings, OT, M. Vercauteren, \\ MD \\ Department of Physical Medicine and Orthopaedic Surgery, Ghent University Hospital, \\ De Pintelaan 185, B-9000 GENT, Belgium.
}

\section{Summary}

The results of 22 procedures ( 8 for elbow extension, 14 for hand rehabilitation) on the upper limb in tetraplegia are reported. To evaluate the effect of surgery an objective hand function test is presented. The few complications after surgery must be attributed to the material used.

Key words: Tetraplegia; Hand surgery; Rehabilitation; Spinal cord injury; Elbow extension.

Since Erik Moberg (1978) described in detail the possibilities of surgical restoration of the upper limb in tetraplegia, there has been a renewed interest in restoring the functional capabilities by tendon transfers. As many as $75 \%$ of tetraplegics would prefer restoration of their upper limb function to that of any other lost function. Consequently, we think it worthwhile to evaluate the benefit each patient would derive from surgery. Our selection of patients, the surgical procedure, the rehabilitation method and the pre- and post-operative assessment are reported.

\section{Patient selection}

In our department, non-surgical care of the paralysed hand is the method-ofchoice. A tendon transfer is performed in only a small number of patients in whom conservative means have failed. Since the cervical spine injury is often stabilised by internal fixation, rehabilitation can be started early.

Approximately 6 months post-injury, a functional assessment is obtained and treatment planned. Since training after tendon transfer takes many weeks to months, patients prefer not to delay surgery for too long. Candidates for surgery are shown a videotape of a patient who underwent the same procedure. The operation is performed 6 months after the injury if there are no signs of further recovery. The assessment of motor function is based upon the system presented at 
Table I International classification for surgery of the hand in tetraplegia (Giens, 1984)

\begin{tabular}{ll}
\hline Group & Motor \\
\hline $0(\mathrm{Cu}): 0$ & No grade 4 muscle below elbow \\
$0(\mathrm{Cu}): 1$ & Brachioradialis $(\mathrm{Br})$ \\
$0(\mathrm{Cu}): 2$ & Br + extensor carpi radialis longus (ECRL) \\
$0(\mathrm{Cu}): 3$ & Same + ECR brevis (ECRB) \\
$0(\mathrm{Cu}): 4$ & Same + pronator teres (PT) \\
$0(\mathrm{Cu}): 5$ & Same + flexor carpi radialis (FCR) \\
$0(\mathrm{Cu}): 6$ & Same + finger extensors \\
$0(\mathrm{Cu}): 7$ & Same + thumb extensor \\
$0(\mathrm{Cu}): 8$ & Same + partial digital flexors \\
$0(\mathrm{Cu}): 9$ & Lacks only intrinsics \\
\hline
\end{tabular}

the Second International Conference on Surgical Rehabilitation of the Upper Limb in Tetraplegia (Giens, 1984) (Table I). The sensory classification consists of two categories: 'O' for ocular afferent impulses and ' $\mathrm{Cu}$ ' for cutaneous afferent impulses (two point discrimination $12 \mathrm{~mm}$ or less). As Moberg (1978) recommended, we only perform reversible procedures. Severe spasticity is a contraindication. The power of the muscle to be transplanted, should be at least grade 4 .

Consequently, prior to surgery, much emphasis is placed on increasing the strength of the brachioradialis and posterior portion of the deltoideus. If both extremities are at the same level of classification, the dominant limb is always operated on first.

Although Moberg decreed that only one side must be reconstructed if cutaneous sensation is inadequate, we sometimes perform a bilateral procedure at the patient's request: stabilisation of the hand is possible without an orthesis and so both hands can be used for bimanual activities.

Finally, the patient must be highly motivated and willing to co-operate in a fairly prolonged programme.

The operation is performed by a surgeon with much experience in this field and the patient is trained by the same therapist throughout the entire rehabilitation period.

\section{Operative technique}

The first step in reconstructive surgery is the restoration of active elbow extension. Without this procedure, the brachioradialis cannot be transferred since it is an elbow flexor. Several techniques for elbow extension have been advanced.

Moberg (1978) proposed a transfer of the posterior portion of the deltoid to the triceps with interlacing of the extensor tendons of the foot. The idea was not new: Merle d'Aubigné already introduced it in 1949. In 1938, Ober and Barr treated triceps weakness by transposition of the brachioradialis, rerouting this muscle at the elbow in a more posterior direction. We were not able to use this technique since we needed the brachioradialis for transfer into the hand.

In 1954, Friedenberg published his experience with a transfer of the biceps to the triceps aponeurosis. Zancolli (1975) still uses this technique if the supinator is functioning. Schottstaedt et al. (1958) reported the creation of active elbow 
extension using the latissimus dorsi, but since this muscle is essential to stabilisation of the body in a wheelchair, it is not eligible for transfer.

In other techniques, the interlacing between deltoid and triceps is obtained by means of fascia lata strips (Hentz et al., 1976) or the tibialis anterior tendon (Freehafer et al., 1984).

We initially opted for the Moberg technique ( 2 cases) but, because of the long period of immobilisation ( 6 weeks in extension, gain of $10^{\circ}$ of flexion a week), we have abandoned it in favour of the Castro-Sierra and Lopez-Pita procedure (6 cases) (1983). In the latter technique, the distal portion of the posterior deltoid is freed with a flap of periosteum. Two parallel incisions are made in the middle of the triceps tendon, the central portion of the tendon is freed with a periosteal flap and folded onto the deltoid periosteal flap where it is sutured. The angle of reflection of the triceps tendon is reinforced with Dacron. The technique has the advantage that only the arm is operated upon and that the immobilisation period is much shorter. Perhaps extension will diminish with time when the angle of reflection ravels out (Moberg, 1986).

Using the Moberg basic procedure, we have restored hand function in 7 patients. The technique consists of:

1. The construction of a wrist extensor using the brachioradialis: transfer of brachioradialis to ECRB.

2. Tenodesis of the flexor pollicis longus into the radius.

3. Stabilisation of the thumb interphalangeal joint with a Kirschner wire.

4. Resection of the annular ligament at the metacarpophalangeal joint of the thumb.

With active wrist extension, the flexor tenodesis presses the thumb against the index (key-grip). The grip opens by gravity.

When the brachioradialis and extensor carpi radialis longus are available for transfer, Zancolli (1975) proposes a two-stage reconstruction which we performed in 2 cases.

\section{Extensor phase}

1. Tenodesis of the abductor pollicis longus, extensor pollicis longus and extensor digitorum into the radius.

2. Lasso operation.

3. Arthrodesis of the thumb interphalangeal joint.

Flexor phase

1. Transfer of extensor carpi radialis longus of flexor digitorum profundus.

2. Transfer of brachioradialis to flexor pollicis longus.

In 1 case, we have used a variation of the House technique (1976)

1. Tenodesis of abductor pollicis longus, extensor pollicis longus and extensor digitorum into the radius.

2. Transfer of the accessory extensor carpi radialis to the flexor pollicis longus and the extensor carpi radialis longus to the flexor digitorum profundus.

3. Adduction-opponens plasty: transfer of the brachioradialis to the paralysed flexor superficialis IV as an in situ graft rerouted around a palmar pulley to the thumb. 
In another patient we transferred the brachioradialis to the abductor pollicis longus and extensor pollicis longus, and the extensor carpi radialis longus to the flexor digitorum profundus and flexor pollicis longus.

In a patient with good finger flexion, finger and thumb extension was improved by transferring the brachioradialis to the extensor digitorium communis and the extensor pollicis longus.

In 2 patients finger flexion was improved by transferring the extensor carpi radialis longus to the flexor pollicis longus and the brachioradialis to the flexor digitorum profundus. Patients and procedures are presented in Table II.

Table II

\begin{tabular}{|c|c|c|c|c|c|c|}
\hline Case & $\begin{array}{l}\text { Age } \\
\text { Sex }\end{array}$ & $\begin{array}{l}\text { Level fracture- } \\
\text { dislocation }\end{array}$ & Classification & Triceps & $\begin{array}{l}\text { Procedure } \\
\text { hand }\end{array}$ & $\begin{array}{l}\text { Procedure } \\
\text { elbow }\end{array}$ \\
\hline \multirow[t]{2}{*}{ 1. $\mathrm{RV}$} & $17 M$ & C3-C4-C5 & R $0: 1$ & - & Moberg & Moberg \\
\hline & & & L $0: 1$ & - & - & - \\
\hline \multirow[t]{2}{*}{ 2. MF } & $22 \mathrm{~F}$ & $\mathrm{C} 4-\mathrm{C} 5$ & R $0: 1$ & - & Moberg & - \\
\hline & & & L $0 \mathrm{Cu}: 3$ & + & - & - \\
\hline \multirow[t]{2}{*}{ 3. EM } & $44 M$ & $\mathrm{C} 4-\mathrm{C} 5$ & R $0 \mathrm{Cu}: 3$ & + & $\operatorname{Moberg}(-\mathrm{Br})$ & - \\
\hline & & & L $0: 1$ & - & - & - \\
\hline \multirow[t]{2}{*}{ 4. EG } & $26 M$ & $\mathrm{C} 4-\mathrm{C} 5$ & R $0: 1$ & - & Moberg & Moberg \\
\hline & & & L $0: 0$ & - & - & - \\
\hline \multirow[t]{3}{*}{ 5. GM } & $25 \mathrm{M}$ & $\mathrm{C} 7-\mathrm{T} 1$ & R $0 \mathrm{Cu}: 5$ & + & $\mathrm{Br} \rightarrow \mathrm{APL}$ & - \\
\hline & & & & & $\begin{array}{l}\text { \& EPL } \\
\text { ECRL } \rightarrow \text { FDP } \\
\& \text { FPL }\end{array}$ & \\
\hline & & & L $0 \mathrm{Cu}: 6$ & + & - & - \\
\hline \multirow[t]{2}{*}{ 6. PG } & $24 M$ & $\mathrm{C} 5-\mathrm{C} 6$ & R $0 \mathrm{Cu}: 4$ & - & - & Castro-Sierra \\
\hline & & & L $0 \mathrm{Cu}: 4$ & - & - & - \\
\hline \multirow[t]{3}{*}{ 7. AV } & $24 M$ & $\mathrm{C} 6-\mathrm{C} 7$ & $\mathrm{R} 0 \mathrm{Cu}: 3$ & + & $\begin{array}{l}\text { 1. APL/EPL } \rightarrow \\
\text { radius } \\
\text { E. dig. } \rightarrow \\
\text { radius }\end{array}$ & - \\
\hline & & & & & $\begin{array}{l}\text { 2. Ac. ECR } \rightarrow \text { FPL } \\
\text { FCRI } \rightarrow \text { FDP } \\
\mathrm{Br} \rightarrow \text { FDS IV }\end{array}$ & \\
\hline & & & L $0: 2$ & + & - & - \\
\hline \multirow[t]{2}{*}{ 8. RV } & $34 \mathrm{M}$ & $\mathrm{C} 4-\mathrm{C} 5$ & R $0: 1$ & - & Moberg & Castro-Sierra \\
\hline & & & L $0: 1$ & - & $\begin{array}{c}\text { Moberg }+ \\
\text { Tenodesis } \\
\text { FDP } 2 \text { and } 3\end{array}$ & Castro-Sierra \\
\hline \multirow[t]{2}{*}{ 9. $\mathrm{AD}$} & $35 \mathrm{M}$ & Ependymoma & R $0: 3$ & - & Zancolli & Castro-Sierra \\
\hline & & & $\begin{array}{c}\text { L } 0: 5 \\
+ \text { finger flexion }\end{array}$ & - & $\begin{array}{l}\mathrm{Br} \rightarrow \mathrm{EDC} \\
\& \mathrm{EPL}\end{array}$ & Castro-Sierra \\
\hline \multirow[t]{2}{*}{ 10. DB } & $22 M$ & Spinal haemangioma & R $0: 3$ & + & Zancolli & - \\
\hline & & $\mathrm{C} 7$ & L $0: 3$ & + & - & - \\
\hline \multirow[t]{2}{*}{ 11. VP } & $21 \mathrm{M}$ & $\mathrm{C} 7-\mathrm{T} 1$ & R $0 \mathrm{Cu}: 7$ & + & $\begin{aligned} \mathrm{ECRL} & \rightarrow \mathrm{FPL} \\
\mathrm{Br} & \rightarrow \mathrm{FDP}\end{aligned}$ & - \\
\hline & & & L $0 \mathrm{Cu}: 9$ & + & - & - \\
\hline \multirow[t]{2}{*}{ 12. $\mathrm{CB}$} & $24 M$ & C5-C6 & R $0: 1$ & - & Moberg & Castro-Sierra \\
\hline & & & L $0: 1$ & - & - & \\
\hline \multirow[t]{2}{*}{ 13. RR } & $46 M$ & $\mathrm{C} 6-\mathrm{C} 7$ & R $0: 5$ & + & $\begin{array}{l}\mathrm{ECRL} \rightarrow \mathrm{FPL} \\
\mathrm{Br} \rightarrow \mathrm{FDP}\end{array}$ & - \\
\hline & & & L $0 \mathrm{Cu}: 8$ & + & - & - \\
\hline
\end{tabular}




\section{Post-operative management}

Following the restoration of elbow extension, a well padded long arm cylinder cast is applied to hold the elbow in $10^{\circ}$ of flexion. The immobilisation period is 4 weeks. Active extension exercises are started with a gain of $10^{\circ}$ of flexion a week, first with gravity eliminated and then partially against the weight of the forearm.

When full active extension cannot be achieved, no further flexion is allowed. Since the patients always are too eager to gain flexion, they are fitted with a removable light Orfit $^{\circledR}$ orthesis (thermomalleable plastic) incorporating an elbow hinge: full extension is possible, but flexion can be blocked in the required position. The orthesis is worn during the night (Fig. 1).

Following a Moberg and Zancolli procedure, active exercises are started after an immobilisation period: after a Moberg procedure a plaster above the elbow, wrist in slight dorsiflexion, thumb in adduction for 4 weeks. After a Zancolli procedure a plaster below the elbow, with wrist, thumb and fingers in extension; after the flexor phase a plaster above the elbow with the wrist in slight dorsiflexion (4 weeks). Training in the use of the grip is gradual and adapted to the individual's special needs. No routine programme can be established. Undue tension on the transplanted muscles must be avoided and no pain-producing motion is allowed.

Wheelchair propulsion and transfers are prohibited during 2 months. The patients are trained at least twice a day by the same occupational therapist.

\section{Complications}

Kirschner migration was observed in a distal direction in 2 cases. Because of this

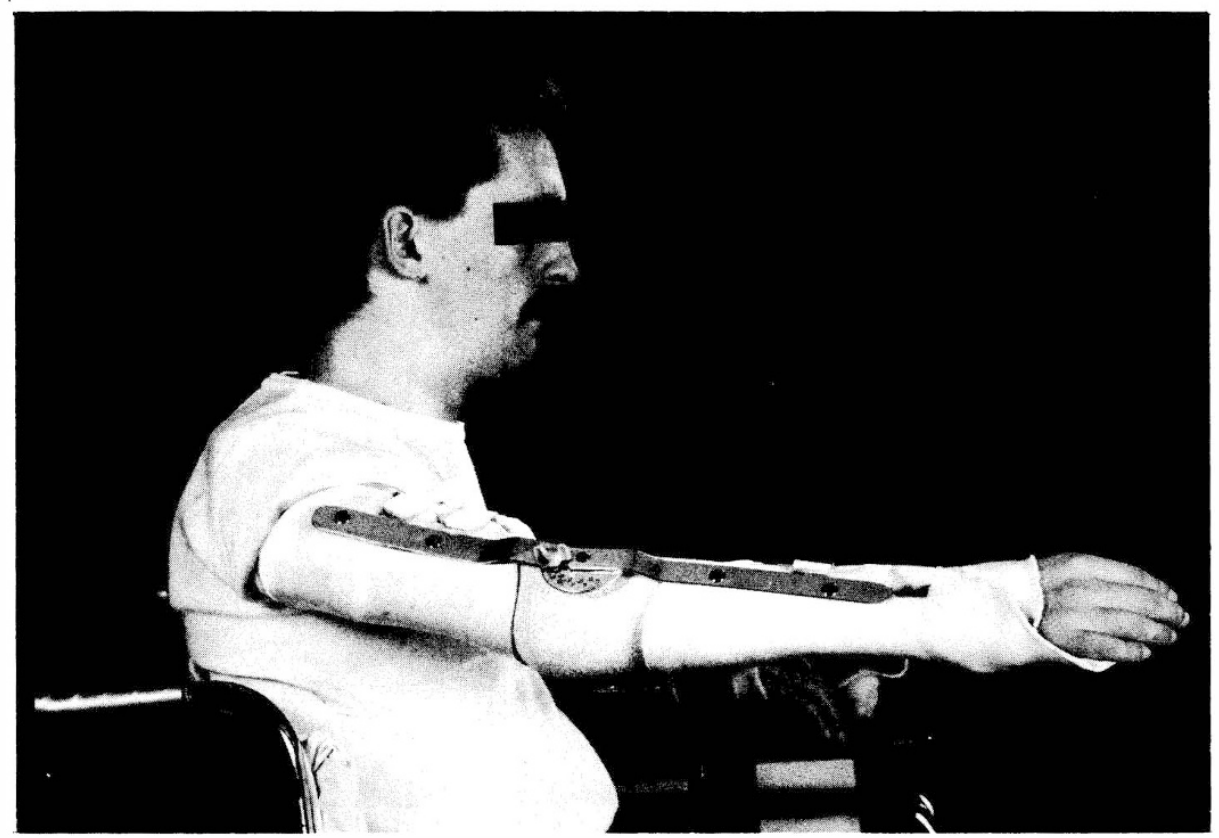

Figure 1 Removable light Orfit ${ }^{\circledR}$ orthesis. Orfit ${ }^{\circledR}$ is a thermomalleable plastic. 
complication we started using threaded wires but two of them fractured subsequently (Hiersche and Waters, 1985).

The force of the key-grip diminishes when the grip is less used. One patient was not able to roll up the finger to meet the thumb and underwent a flexor tenodesis of the second and third finger. In 1 case, passive abduction of the thumb was improved with a rubber splint.

The transfer had to be released in 1 patient and tightened in another.

One patient who underwent a Casto-Sierra procedure fell on the arm and never regained good function. Surgical exploration disclosed a rupture of the transfer which was resutured.

\section{Results}

Fourteen hands and 8 elbows have been reconstructed in 13 patients. A bilateral elbow and hand procedure was carried out twice. The patients were evaluated at the completion of their rehabilitation period.

All patients regained active elbow extension against gravity (grade 3), some against resistance (grade 4) (Table III).

The reconstructed hand function was measured with the Jamar dynamometer and expressed in gram. Pinch gauge and wrist extension against resistance also were expressed in gram (Table IV).

Table III Restoration of elbow extension

\begin{tabular}{lcc}
\hline Procedure & Grade & Number \\
Moberg & 3 & 2 \\
Castro-Sierra & 3 & 4 \\
Castro-Sierra & 4 & 2 \\
Total & & 8 \\
\hline
\end{tabular}

Table IV

\begin{tabular}{|c|c|c|c|c|c|}
\hline & & Hand & Jamar/g & $\begin{array}{l}\text { Pinch } \\
\text { gauge/g }\end{array}$ & $\begin{array}{l}\text { Wrist } \\
\text { ext./g }\end{array}$ \\
\hline 1. & R0:1 - & Moberg & $0 \rightarrow$ & $0 \rightarrow 500$ & $0 \rightarrow \quad 250$ \\
\hline 2. & $\mathrm{R} 0: 1-$ & Moberg & $0 \rightarrow \quad 0$ & $0 \rightarrow 1500$ & $0 \rightarrow 1850$ \\
\hline 3. & ROCu:3 + & Moberg (- Br) & $0 \rightarrow 1000$ & $0 \rightarrow 1000$ & 3000 \\
\hline & R0:1 & Moberg & $0 \rightarrow \quad 0$ & $0 \rightarrow 250$ & $0 \rightarrow 750$ \\
\hline & ROCu:5 + & $\begin{array}{l}\mathrm{Br} \text { APL \& EPL } \\
\text { ECRL } \rightarrow \text { FDP \& FPL }\end{array}$ & $0 \rightarrow 8000$ & $0 \rightarrow 1500$ & 3000 \\
\hline 7. & $\mathrm{ROCu}: 3+$ & House & $0 \rightarrow 10000$ & $0 \rightarrow 4000$ & 3500 \\
\hline $8 \mathrm{~A}$. & $\mathrm{R} 0: 1-$ & Moberg & $0 \rightarrow 1500$ & $0 \rightarrow 500$ & $0 \rightarrow 2500$ \\
\hline $8 B$. & L0:1 - & $\begin{array}{l}\text { Moberg }+ \text { tenodesis } \\
\text { FDP } 2 \& 3\end{array}$ & $0 \rightarrow \quad 500$ & $0 \rightarrow \quad 250$ & $0 \rightarrow 2000$ \\
\hline 9A. & $\mathrm{R} 0: 3$ - & Zancolli & $0 \rightarrow 6000$ & $0 \rightarrow 1500$ & 3000 \\
\hline 9B. & L0:5 - & $\mathrm{Br} \rightarrow \mathrm{EDC} \& \mathrm{EPL}$ & 2000 & 250 & 6000 \\
\hline 10. & R0:3 + & Zancolli & $0 \rightarrow 7500$ & $0 \rightarrow 1500$ & 3000 \\
\hline 11. & $\mathrm{ROCu}: 7+$ & $\begin{array}{c}\mathrm{ECRL} \rightarrow \mathrm{FPL} \\
\mathrm{Br} \rightarrow \mathrm{FDP}\end{array}$ & $0 \rightarrow 9000$ & $0 \rightarrow 5500$ & 3000 \\
\hline 12. & R0:1 - & Moberg & $0 \rightarrow \quad 0$ & $0 \rightarrow 250$ & $0 \rightarrow 1000$ \\
\hline 13. & $\mathrm{R} 0: 5+$ & $\begin{array}{c}\mathrm{ECRL} \rightarrow \mathrm{FPL} \\
\mathrm{Br} \rightarrow \mathrm{FDP}\end{array}$ & $0 \rightarrow 7000$ & $0 \rightarrow 1750$ & 3500 \\
\hline
\end{tabular}


We also studied the relation of residual voluntary motor function to pinch strength (Waters et al., 1985) (Fig. 2).

To evaluate the effect of surgery an objective hand function test before and after surgery is imperative; the authors also studied the improvement in ADL performance. The test is performed by the therapist and surgeon of the same team. The hand and arm function test is made up of 9 items (Fig. 3).

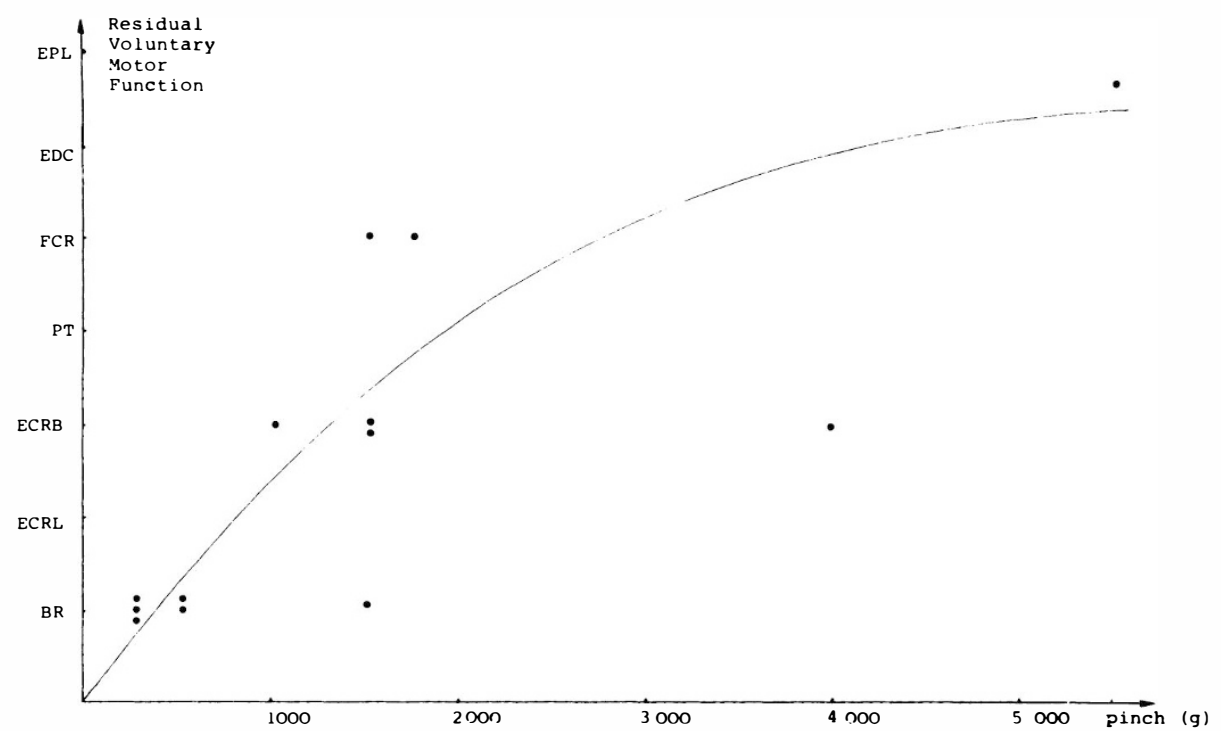

Figure 2 Relationship of residual voluntary motor function to pinch strength.

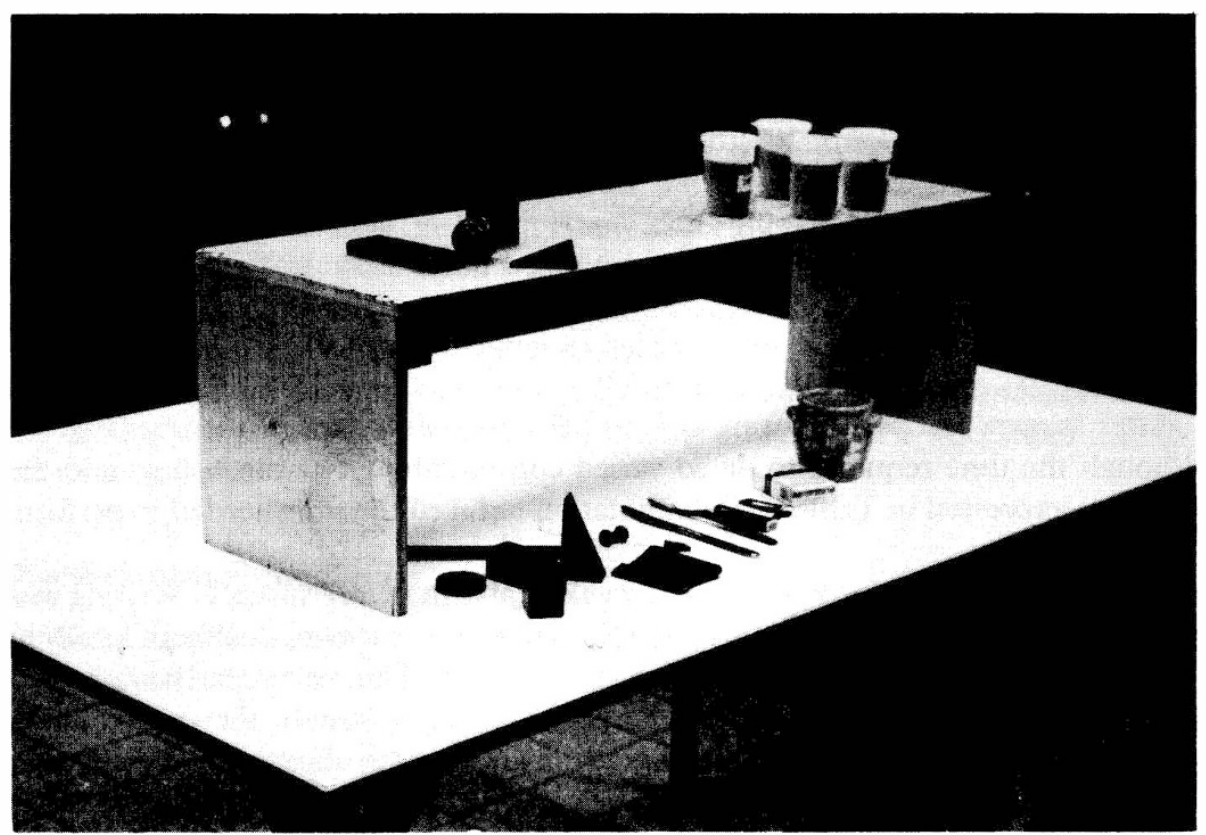

Figure 3 Test battery: it consists of bowls, daily objects such as a cup, knife, toothbrush, lighter, key, sharpener, nut and screw and purse. The patient is asked to lift the object from the table and place it on a wooden board. 


\begin{tabular}{lccc} 
Table V & & \\
\hline Item & Minimum score & Maximum score & Mean \\
\hline 1 & $39^{\prime \prime}$ & $1^{\prime} 54^{\prime \prime}$ & $1^{\prime} 07^{\prime \prime}$ \\
2 & $2^{\prime} 25^{\prime \prime}$ & $4^{\prime} 14^{\prime \prime}$ & $3^{\prime} 15^{\prime \prime}$ \\
3 & $28^{\prime \prime}$ & $40^{\prime \prime}$ & $33^{\prime \prime}$ \\
4 & $47^{\prime \prime}$ & $4^{\prime} 19^{\prime \prime}$ & $2^{\prime} 13^{\prime \prime}$ \\
5 & $28^{\prime \prime}$ & $57^{\prime \prime}$ & $43^{\prime \prime}$ \\
6 & $1^{\prime} 04^{\prime \prime}$ & $2^{\prime} 32^{\prime \prime}$ & $1^{\prime} 52^{\prime \prime}$ \\
7 & $29^{\prime \prime}$ & $31^{\prime \prime}$ & $31^{\prime \prime}$ \\
8 & $49^{\prime \prime}$ & $2^{\prime} 01^{\prime \prime}$ & $1^{\prime} 47^{\prime \prime}$ \\
9 & $32^{\prime \prime}$ & $1^{\prime} 45^{\prime \prime}$ & $1^{\prime} 02^{\prime \prime}$ \\
\hline
\end{tabular}

Table VI

\begin{tabular}{lccc}
\hline Item & $\begin{array}{c}\text { Before surgery } \\
\text { mean time }\end{array}$ & $\begin{array}{c}\text { After surgery } \\
\text { mean time }\end{array}$ & $\begin{array}{c}\text { Mean gain } \\
\text { or loss }\end{array}$ \\
\hline 1 & $07^{\prime \prime}$ & $08^{\prime \prime}$ & $01^{\prime \prime}$ loss \\
2 & $2^{\prime} 03^{\prime \prime}$ & $30^{\prime \prime}$ & $1^{\prime} 33^{\prime \prime}$ \\
3 & $08^{\prime \prime}$ & $07^{\prime \prime}$ & $01^{\prime \prime}$ \\
4 & $30^{\prime \prime}$ & $18^{\prime \prime}$ & $12^{\prime \prime}$ \\
5 & $10^{\prime \prime}$ & $09^{\prime \prime}$ & $01^{\prime \prime}$ \\
6 & $37^{\prime \prime}$ & $28^{\prime \prime}$ & $09^{\prime \prime}$ \\
7 & $08^{\prime \prime}$ & $07^{\prime \prime}$ & $01^{\prime \prime}$ \\
8 & $28^{\prime \prime}$ & $36^{\prime \prime}$ & $08^{\prime \prime}$ loss \\
9 & $10^{\prime \prime}$ & $07^{\prime \prime}$ & $03^{\prime \prime}$ \\
\hline
\end{tabular}

1. Transfer of 4 bowls, $50 \mathrm{~g}$ each.

2. Grasp and transfer of 10 daily objects (cup, knife, toothbrush, lighter, key, sharpener, nut and screw, purse).

3. Transfer of 4 bowls, $100 \mathrm{~g}$ each.

4. Grasp and transfer of 10 different objects of natural wood (ball, cube, beam, slat, disc and triangle).

5. Transfer of 4 bowls, $150 \mathrm{~g}$ each.

6. Grasp and transfer of 10 different painted objects (smooth surface).

7. Transfer of 4 bowls, $200 \mathrm{~g}$ each.

8. Writing of a sentence consisting of 18 letters.

9. Transfer of 4 bowls, $250 \mathrm{~g}$ each.

After surgery, all patients were able to perform the 9 items of the test (Fig. 4), although the time required to do so varied considerably. The mean time and the range are expressed in Table $\mathrm{V}$. Rehabilitation reduced the time needed to perform the test.

In the groups 0:3 to 0:7 key-grip was weak or absent before surgery. Writing was possible with passive fixation of a pen to the hand. The patients used both hands to grasp and hold objects, but dropped many of them. This particularly applied to item 2. Although it took the patients longer to complete item 8 , they were able to write without any adaptations. The patients could handle objects more easily and did not drop them so often (Table VI).

The following activities of daily living were evaluated: eating, washing, grooming, shaving, dressing and transfers. They were evaluated using the following scoring system: 


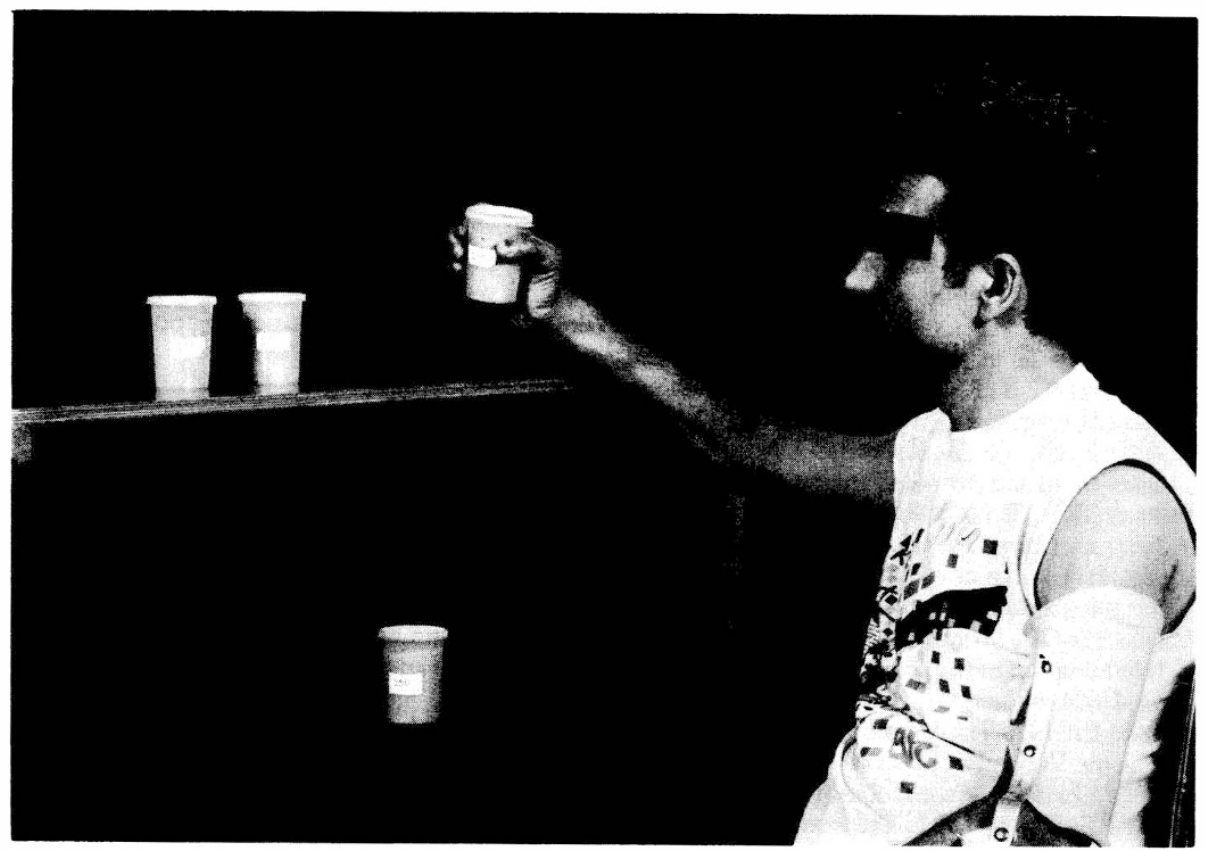

Figure 4 Patient performing part of hand function test.

0 : Totally dependent.

1: With physical help.

2: With gadget.

3: Totally independent.

In group 0:1 the patients were totally dependent before surgery. After surgery the activities 1 to 3 could be performed with the use of a gadget. Transfers were possible with physical help. After an elbow procedure, patients of group 0:3 were all able to turn in bed, push up in a wheelchair and stabilise themselves in a sitting position. Following hand surgery, a minimum of adaptations were necessary and less physical help was needed for transfers. In group 0:4 to 0:7 adaptations were no longer required and all activities of daily living could be performed independently. Car driving was possible and the patients managed to pull their wheelchair into the car without help.

\section{Discussion and conclusion}

Careful patient selection, based not only on the level of spinal injury, but also on the residual motor and sensory functional resources, is mandatory before reconstruction is contemplated. Simplicity in the procedures attempted in tetraplegics is essential. If lacking, elbow extension is restored first. The patients always regained full elbow extension against gravity, a few even against resistance. After Moberg and other transfer procedures, the majority of patients experienced consistent improvement in prehension. This was quantified by a scoring and grading system for the assessment of hand function and ADL before and after 
surgery. No patient lost any function. The improvement in upper limb function not only facilitated the self-care but also stimulated the development of personal interests, e.g. study, sports, hobbies.

\section{References}

Castro-Sierra A, Lopez-Pita A 1983 A new surgical technique to correct triceps paralysis. Hand 15:42-46.

Freehafer AA, Kelly CM, PeCKham PH 1984 Tendon transfer for the restoration of upper limb function after a cervical spinal cord injury. Fournal of Hand Surgery 9-A:887-893.

FRIEDENBERG ZB 1954 Transposition of the biceps brachii for triceps weakness. Fournal of Bone and Foint Surgery 36-A:656-658.

HENTZ VR, BROWN M, KEOSHIAN LA 1983 Upper limb reconstruction in quadriplegia: functional assessment and proposed treatment modifications. Fournal of Hand Surgery 8:119-131.

HiERSCHE DL, WATERS RL 1985 Interphalangeal fixation of the thumb in Mobergs key-grip procedure. Fournal of Hand Surgery 10:30-32.

HoUSE JH, GWATHMEY FW, LUNDSGAARD DK 1976 Restoration of strong grasp and lateral pinch in tetraplegia due to cervical spinal cord injury. Fournal of Hand Surgery 1:152-159.

MCDOWELl CL, MOBERg EA, HouSE JH 1986 The second international conference on surgical rehabilitation of the upper limb in tetraplegia (quadriplegia). Fournal of Hand Surgery 11-1:604-608.

MoBERg EA 1978 The Upper Limb In Tetraplegia: A New Approach to Surgical Rehabilitation. Georg Thieme Verlag Publishers, Stuttgart.

MOBERG EA 1986 Personal communication.

OBER FRE, BARR JS 1938 Brachioradialis muscle transposition for triceps weakness. Surgery Gynecology and Obstetrics 67:105-107.

SCHOTTSTAEDT ER, LARSEN LJ, BOST FC 1958 The surgical reconstruction of the upper extremity paralyzed by poliomyelitis. Fournal of Bone and foint Surgery 40-A:633-643.

WATERS R, MOORE KR, GRABOFF SR, PARIS K 1985 Brachioradialis to flexor pollicis longus tendon transfer for active lateral pinch in the tetraplegic. Fournal of Hand Surgery 10-A:385-391.

ZANCOLLI EA 1975 Surgery for the quadriplegic hand with active strong wrist extension preserved: a study of 97 cases. Clinical Orthopaedics $\mathcal{E}$ Related Research 112:101-113. 